Article

\title{
New Evidence for Cross Talk between Melatonin and Mitochondria Mediated by a Circadian-Compatible Interaction with Nitric Oxide
}

\author{
Paolo Sarti ${ }^{1,2, *}$, Maria Chiara Magnifico ${ }^{1}$, Fabio Altieri ${ }^{1}$, Daniela Mastronicola ${ }^{2}$ and \\ Marzia Arese ${ }^{1}$
}

1 Department of Biochemical Sciences, Sapienza University of Rome, Rome 00185, Italy; E-Mails: mariachiara.magnifico@uniroma1.it (M.C.M.); fabio.altieri@uniroma1.it (F.A.); marzia.arese@uniroma1.it (M.A.)

2 CNR Institute of Molecular Biology and Pathology, Rome 00185, Italy;

E-Mail: daniela.mastronicola@uniroma1.it

* Author to whom correspondence should be addressed; E-Mail: paolo.sarti@uniroma1.it; Tel.: +39-6-4450291 or +39-6-49910944; Fax: +39-6-4440062.

Received: 22 March 2013; in revised form: 16 May 2013 / Accepted: 16 May 2013 /

Published: 28 May 2013

\begin{abstract}
Extending our previous observations, we have shown on HaCat cells that melatonin, at $\sim 10^{-9} \mathrm{M}$ concentration, transiently raises not only the expression of the neuronal nitric oxide synthase (nNOS) mRNA, but also the nNOS protein synthesis and the nitric oxide oxidation products, nitrite and nitrate. Interestingly, from the cell bioenergetic point of view, the activated NO-related chemistry induces a mild decrease of the oxidative phosphorylation (OXPHOS) efficiency, paralleled by a depression of the mitochondrial membrane potential. The OXPHOS depression is apparently balanced by glycolysis. The mitochondrial effects described have been detected only at nanomolar concentration of melatonin and within a time window of a few hours' incubation; both findings compatible with the melatonin circadian cycle.
\end{abstract}

Keywords: nitric oxide; cell bioenergetics; respiratory chain; circadian rhythm; cell culture; Warburg effect; reactive oxygen; nitrogen species 


\section{Introduction}

Melatonin, the $\mathrm{N}$-acetyl-5-methoxytryptamine, is an amphiphilic molecule with remarkable antioxidant properties [1,2]. Originally recognized as the hormone of the pineal gland, melatonin is produced also by other extrapineal sites [3-8]. World-widely recommended as a pharmaceutical tool for elderly people with sleep disorders, melatonin is responsible for regulation of the sleep-wake cycle $[9,10]$. It is involved in a variety of physiological functions [11-13], including modulation of gene transcription [14], blockage of transcriptional factors [15] and control of mitochondrial activities [16]. The antioxidant properties of melatonin have been world-widely recognized, likely accounting for a number of protective effects exerted in different cellular compartments [17]. Melatonin is more effective than the majority of its naturally occurring molecular analogs [18,19], suggesting that the substituents of the central indole structure controls the reactivity of the adducts. Rate constants determined for the reaction of melatonin with hydroxyl radicals are very high, almost diffusion limited, approaching $k \approx 10^{10} \mathrm{M}^{-1} \mathrm{~s}^{-1}$ [20,21]. Despite its common use, the molecular mechanism(s) underlying the functional effects of melatonin, particularly those related to cell bioenergetics, remain as yet only partly understood. The blood circulating melatonin concentration is genetically encoded [22] and varies within individuals [23-26], accounting for the existence of genetically encoded melatonin-dependent human syndromes [27].

As schematically represented in Figure 1, over and above the antioxidant redox function, melatonin exerts its hormonal effects via receptor-mediated signaling and activation of specific mRNAs [12]. At least dealing with mitochondria, both the hormonal and the antioxidant function coexist $[2,16]$ and referenced therein [28]. The experimental evidence suggest that the mitochondrial antioxidant activity is more evident at the higher $(\geq \mu \mathrm{M})$ concentrations of melatonin, while the hormonal-like function can be detected at the lower $(\leq \mathrm{nM})$ concentrations.

Very recently, using HaCat cells in culture, we have shown that $\mathrm{nM}$ melatonin induces the increase of the mRNA expression of neuronal nitric oxide synthase (nNOS) [28]. The mRNA induction was proven to occur within a few hours of cells incubation with melatonin and followed a rise and fall kinetics. The overall process was suggested to be fully compatible with a circadian cycle, mediated by melatonin receptors and with a timing consistent with a nuclear DNA-activated process [28]. The upregulation by melatonin of the nNOS mRNA expression appeared specific, since the eNOS and the iNOS expression was insensitive to melatonin [28]. Interestingly, on a time scale compatible with the

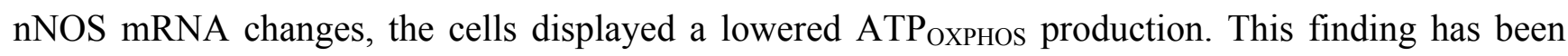
tentatively explained based on the reversible inhibition exerted by the NO on the respiratory chain Complex IV (cytochrome c oxidase, CcOX) [29,30], an event whose pathophysiological meaning is strengthened by the putative existence of a mitochondrial isoform of the nNOS.

In this paper, we report new evidence supporting a melatonin-induced synthesis of the nNOS enzyme occurring within a time scale compatible with the nNOS mRNA, and we show its effect on cell respiration. Over a circadian-compatible time window, we have evaluated the nNOS protein synthesis by HaCat cells incubated with physiological, nanomolar, melatonin. In agreement with previous results [28], we have evaluated those functional parameters, suitable to assess the cell bioenergetic state, correlating them in parallel with changes in composition of the cell culture medium, particularly focusing on the NO end products. The whole picture further suggests that NO chemistry 
plays a role in the mitochondrial circadian cycle [28,31]. The hypothesis is fully consistent with the finding that the production of nitrite and nitrate is also characterized by a circadian night peak [32] and that the nNOS activity is involved in sleep regulation [33,34].

Figure 1. Melatonin on the cell stage. Melatonin interacts with cells in a receptor-dependent or -independent manner. The receptors on the cell membrane, MT1 ( Mel la) and MT2 $(\mathrm{Mel} \mathrm{lb})$, consist of seven transmembrane helices, G protein-coupled. Activating G protein signaling, the receptors mediate a wide variety of effects; among others, inhibition of the adenylate cyclase (AC), with a consequent cyclic AMP (cAMP) decrease, regulation of gene transcription, activation of protein kinase $\mathrm{C}$ subtypes and changes of intracellular $\mathrm{Ca}^{++}$ levels. Independently of receptors, melatonin permeates cell membranes and, owing to its low redox potential, $E_{\mathrm{o}}=-980 \mathrm{mV}$ [21], scavenges the ROS in the cell cytoplasm, mitochondria and nucleus. In the cytoplasm, melatonin maintains GSH homeostasis and interacts with proteins, such as calmodulin $(\mathrm{CaCaM})$, calreticulin and the cytosolic quinone reductase 2 enzyme, (MT3). Melatonin is also a ligand for a nuclear retinoid related orphan nuclear hormone receptor (RZR/RORa) regulating the expression of anti-oxidant enzymes, such as glutathione peroxidase (GPx), glutathione reductase (GRd) and superoxide dismutase (SOD), and downregulating pro-oxidant enzymes, such as the NOSs, particularly the iNOS [35]. Melatonin is accumulated in mitochondria at high concentrations, where it scavenges ROS and RNS. Melatonin also protects cardiolipin from oxidation [36] and prevents respiratory chain complexes, as well as mtDNA from free radical attack, thus ultimately protecting the membrane permeability transition ( $\mathrm{mPT}$ ) pore, thus preventing cell apoptosis.

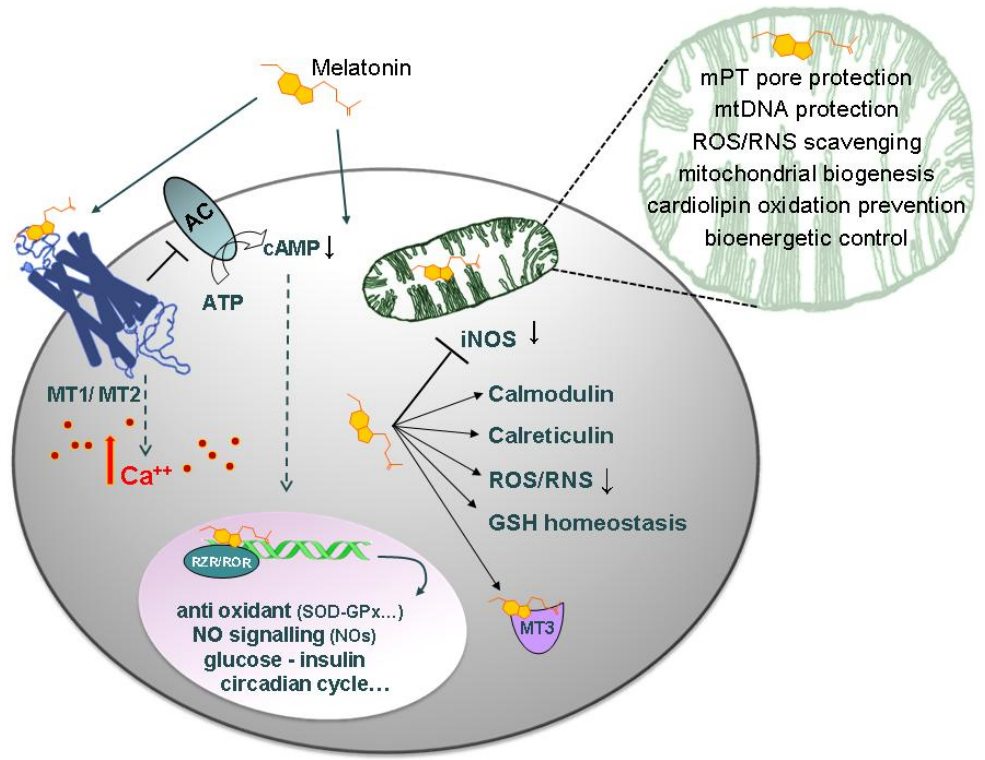

A bioenergetic involvement of melatonin is supported by the effects induced on the respiratory chain, though their interpretation is not always straightforward [16]. Difficulties in comparing data are partly linked to differences in the experimental set up. Experiments have been carried out, in fact, with fully integrated systems, such as animals or cells in culture, but also using isolated mitochondria. In the latter case, regardless of whether the organelles are functionally intact or not, the nuclear signaling-dependent reactions do not occur. In addition, it should be kept in mind that the intracellular 
concentration of melatonin putatively reached under the given conditions, unless directly measured, remains uncertain owing to the ability of different cell organelles, e.g., mitochondria [37], and compartments, e.g., nuclei [38], to accumulate melatonin to a different extent.

\section{Results and Discussion}

\subsection{Experimental Results}

The mitochondrial response to melatonin has been investigated using cultured $\mathrm{HaCaT}$ cells exposed to increasing amounts of melatonin, from 1 to $100 \mathrm{nM}$; the activation of nuclear-dependent reactions was also investigated by carrying the experiments within a time scale of hours.

Figure 2. Time-dependent effects of $\mathrm{nM}$ melatonin on nNOS expression and NOx production. HaCaT cells were incubated with $1 \mathrm{nM}$ melatonin; at the times indicated, the nNOS mRNA (a), nNOS protein (b) and nitrite/nitrate (NOx) production (c) were assayed. (a) QRT-PCR analysis of mRNA expression was performed in the presence of specific primers for nNOS. The relative expression levels were calculated $v s$. untreated controls ( $B$-actin normalized). The maximal mRNA expression at $6 \mathrm{~h}$ (blue). Data $+/-\mathrm{SEM}, n \geq 3$. $* * p \leq 0.01$ vs. control; * $p \leq 0.05$ vs. control; (b) Western blot analysis of nNOS protein. Data shown as fold increase $v s$. the nNOS protein expressed by control cells, as a function of incubation time. The maximal protein synthesis at $8 \mathrm{~h}$ (green). Data $+/-\mathrm{SEM}, n \geq 3$. $* * p \leq 0.01 v s$. control; (c) NOx accumulation measured in the supernatant as a function of time. Data shown as fold increase $v s$. control (untreated). The maximal NOx production at $8 \mathrm{~h}$ (violet). Data $+/-\mathrm{SEM}, n \geq 5$. ** $p \leq 0.01$ vs. control; (d) Time-dependent profile of the expression of the nNOS mRNA (blue) and nNOS protein (green); (e) Western Blot of cells incubated $8 \mathrm{~h}$ with $1 \mathrm{nM}$ melatonin and controls (CTR); $\alpha$-tubulin as reference.

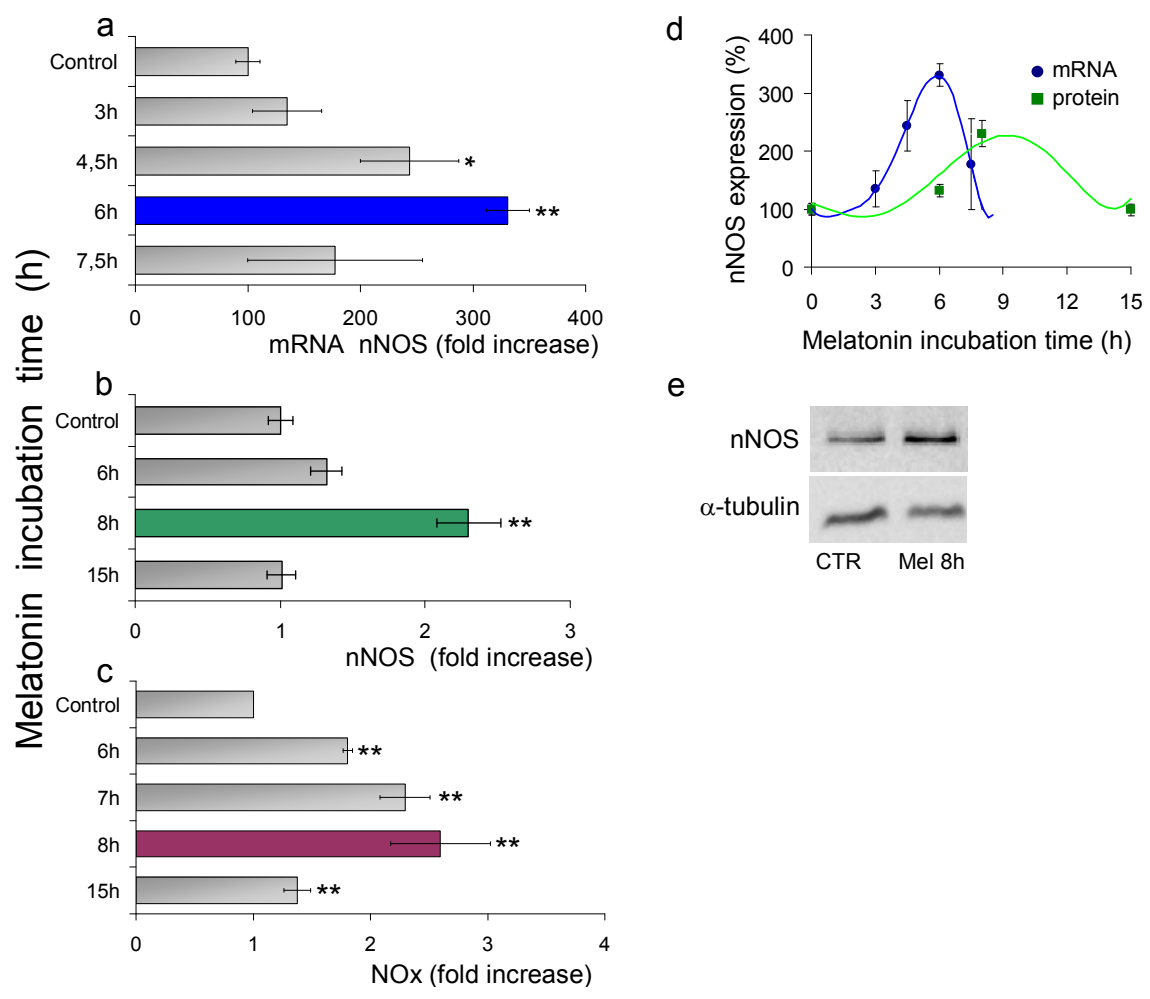




\subsubsection{Neuronal NOS (nNOS) Expression and NOx Production}

Cells were incubated with melatonin $(1 \mathrm{nM})$ for up to $\sim 15 \mathrm{~h}$, and the bioavailability of nitric oxide has been evaluated indirectly by following changes of the cellular NOSs. As shown in Figure 2, the nNOS mRNA level and the nNOS protein expression changed as a function of time, together with the nitrites and nitrates (NOx) concentration, in the culture medium. The nNOS synthesis and the NOx production reach a maximum after $\sim 8 \mathrm{~h}$ incubation, i.e., $\sim 2 \mathrm{~h}$ after cell rising of the nNOS mRNA; noticeably, timing of these processes is consistent with protein synthesis and maturation. The increase of the nNOS mRNA and of the protein concentration both occur in the presence of $1 \mathrm{nM}$ melatonin, falling back to basal levels on a longer time scale, even increasing the concentration of melatonin by orders of magnitude (Figure 3). Interestingly, the maximal effect on the nNOS expression and the NOx accumulation is observed at $\sim 1 \mathrm{nM}$ melatonin, tending to the basal level, with increasing melatonin concentration by one or even two orders of magnitude.

Figure 3. Concentration dependence effect of melatonin (nanomolar) on nNOS expression and NOx production. HaCaT cells were treated with increasing melatonin concentrations $(1,10,100 \mathrm{nM})$. (a) After $6 \mathrm{~h}$ of melatonin incubation, the RNA extracted (10 ng) was retro-transcribed and subjected to QRT-PCR in the presence of specific primers for nNOS. The relative expression levels were calculated $v s$. control after normalization for $\beta$-actin. Data + - SEM, $n=3 . * * p \leq 0.01 v s$. control; (b) NO $x$ accumulation in the supernatant of $\mathrm{HaCaT}$ cells was quantified after $6 \mathrm{~h}$ (light bars) and $8 \mathrm{~h}$ (heavy bars) incubation with increasing melatonin concentrations. Data are expressed as means $+/-\mathrm{SEM}, n \geq 5$. $* * p \leq 0.01$ vs. control.
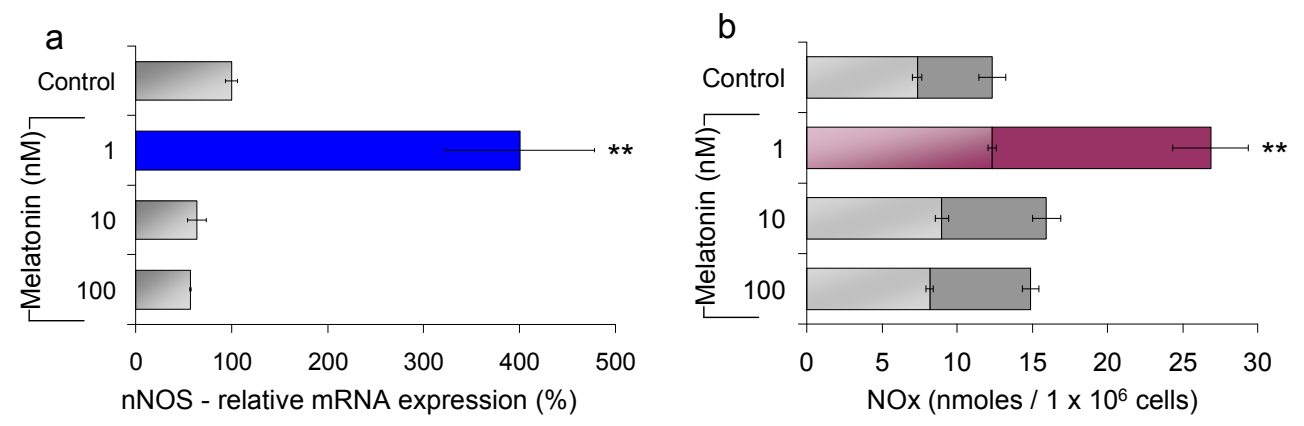

\subsubsection{Mitochondrial Respiration and Membrane Potential}

The spontaneous rate of oxygen consumption was measured amperometrically in intact HaCaT cells respiring on endogenous substrates and incubated $8 \mathrm{~h}$ with increasing amounts of melatonin. As shown in Figure 4a, when cells are treated with $1 \mathrm{nM}$ melatonin, a $\sim 10 \%$ loss of cell respiration is observed; the effect becomes insignificant at higher melatonin concentrations (up to two orders of magnitude), and it is also reverted by addition of the nNOS inhibitor 7-nitroindazole (7N), (Figure 4b). As shown in Figure $4 \mathrm{c}$, following incubation with melatonin, the mitochondrial membrane potential $(\Delta \Psi)$ is lowered, by approximately $20 \%$, compared to control. Moreover, accumulation of the probe is maximal when arginine is removed from the cell culture medium, pointing to a correlation between the import of JC-1 and the availability of the NOS substrate. 
Figure 4. Effect of melatonin on respiration and mitochondrial membrane potential. (a) $\mathrm{HaCaT}$ cells were incubated $8 \mathrm{~h}$ with increasing concentrations of melatonin $(1,10$, $100 \mathrm{nM})$. Respiration was measured and reported as percent of the $\mathrm{O}_{2}$ consumption of control HaCaT cells. Cell density: $3.3 \times 10^{6}$ cells $/ \mathrm{mL}$; medium: Hank's containing $1 \mathrm{~g} / \mathrm{L}$ glucose. Data are expressed as means $+/-\mathrm{SEM}, n \geq 3$. ** $p \leq 0.01 v s$. control; (b) Typical $\mathrm{O}_{2}$ consumption profiles of melatonin-treated $\mathrm{HaCaT}$ cells, in the presence (3, orange) and absence (2, green) of the nNOS inhibitor 7-nitroindazole (7-N); control untreated cells (1, blue). Inset: 1st derivative plot of the traces; (c) Mitochondrial membrane potential measured, following JC-1 accumulation, started by the addition to the cells of nigericin $0.6 \mu \mathrm{M}$ (Nig). Valinomycin (Val) is added (at plateau) to collapse the membrane potential. Excitation wavelength $=490 \mathrm{~nm}$, emission wavelength $=590 \mathrm{~nm}$. Cells maintained in the absence of the NOS substrate arginine (red); control cells (blue). Cells after $8 \mathrm{~h}$ incubation with $1 \mathrm{nM}$ melatonin (green).
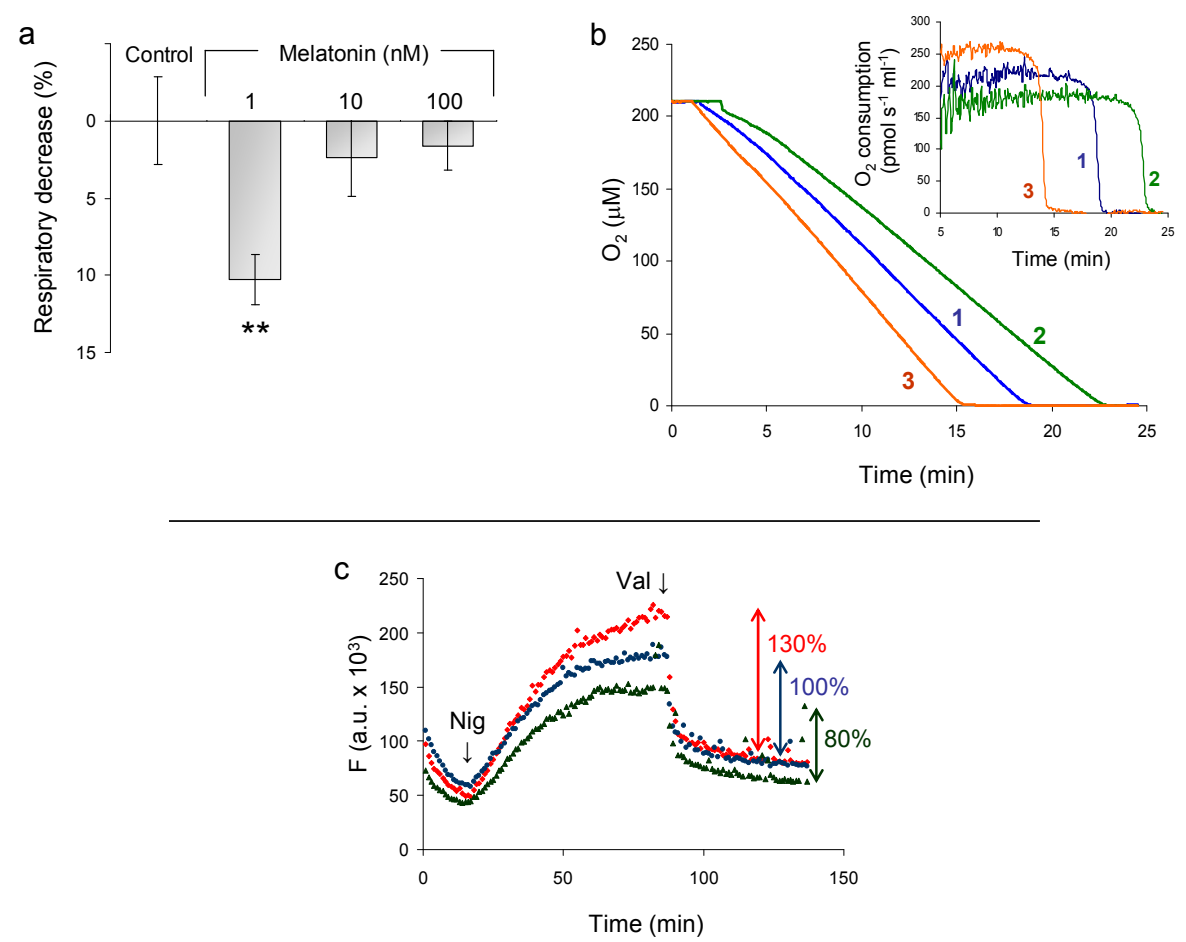

\subsubsection{ATP and Lactate Production}

Melatonin increases the nNOS synthesis; hence, the NO bioavailability of HaCaT cells as probed by the accumulation of the NOx. On the same time scale, the cell $\mathrm{O}_{2}$ consumption is lowered, with predictable outcomes on the mitochondrial bioenergetics $[39,40]$. The cell oxidative phosphorylation and the glycolytic efficiency have been, therefore, evaluated, measuring the concentration of ATP and

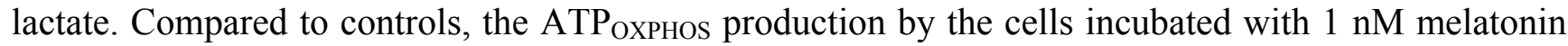
is $\sim 25 \%$ lower (Figure 5a), while their glycolytic efficiency, monitored in parallel, is increased (Figure 5b). The lactate produced under basal conditions is indicative of the glycolytic contribution to ATP synthesis (gray bar in Figure 5b). In the presence of myxothiazol and antimycin inhibiting OXPHOS, some additional lactate is produced, due to glycolytic compensation of ATP loss (Warburg effect) (cyan bar in Figure 5b). This Warburg lactate is indicative of the OXPHOS contribution to ATP 
synthesis. The basal lactate production of the melatonin treated cells is $\sim 65 \%$ of the total lactate, to be compared to $\sim 50 \%$ of the control cells, whereas the Warburg lactate production is $\sim 48 \%$ in the melatonin treated cells and 35\% in controls (Figure 5c). Overall, the data strengthen the hypothesis that several hours' incubation with $1 \mathrm{nM}$ melatonin is able to induce a measurable depression of the OXPHOS function, compensated by glycolysis.

Figure 5. Effect of melatonin on the production of ATP ${ }_{\text {OXPHOS }}$ and lactate. ATP and lactate were assayed in HaCaT cells incubated 6h with melatonin, $1 \mathrm{nM}$. (a) Rate of ATP synthesis: Complex II driven ATP synthesis was measured using cells permeabilized with $60 \mu \mathrm{g} / \mathrm{mL}$ digitonin in the presence of $20 \mathrm{mM}$ succinate, $4 \mu \mathrm{M}$ rotenone and $0.5 \mathrm{mM}$ ADP. ATP measurements carried out according to the luciferin/luciferase assay [41]. Data $+/-$ SEM, $n \geq 14$. ** $p \leq 0.01$ vs. control; (b) Lactate production by HaCaT cells incubated $3 \mathrm{~h}$ with glucose, $1 \mathrm{mM}$, and in the presence and absence of myxothiazol and antimycin A, $10 \mu \mathrm{M}$ each. Basal lactate (gray bar) is produced by the cells in the absence of inhibitors and has been taken as $\approx \mathrm{ATP}_{\text {glycolytic. }}$ The lactate produced in the presence of inhibitors has been taken as the maximal lactate (total, 100\%). The difference between total and basal lactate is the Warburg lactate (cyan); Warburg lactate $\approx$ ATP OXPHOS. Values are the means +/- SEM; $n=4$. ${ }^{*} p \leq 0.05$ vs. control; (c) Synoptic table of the ATP and lactate amounts measured under the conditions described in (a) and (b).

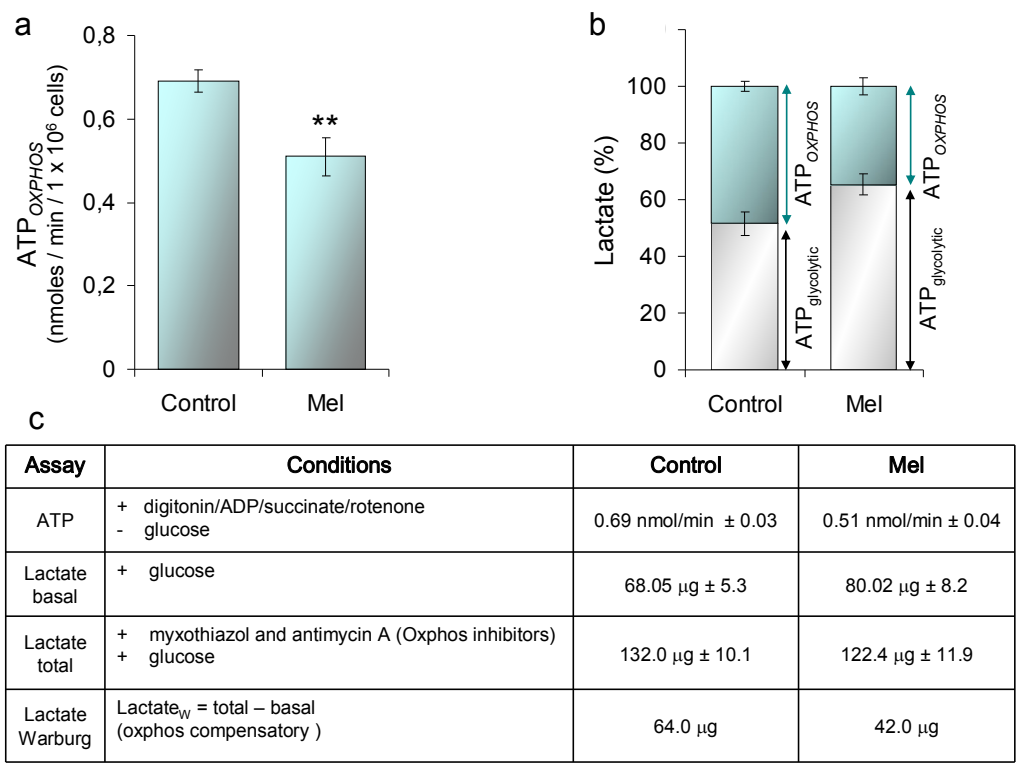

\subsection{Discussion}

\subsubsection{Concentration of Melatonin and Protocol of Administration}

Over the years, concentrations of melatonin from $\sim 10^{-9} \mathrm{M}$ up to $\sim 10^{-4} \mathrm{M}$ have been used to investigate the interactions between melatonin and mitochondria [16]. Measurements have been carried out in the presence of the melatonin cell receptors, as in vivo or in vitro, using cultured cells, but also in the absence of the receptors, when using intact mitochondria or sub-mitochondrial particles. To perform in vivo experiments, melatonin was injected intra-peritoneally (i.p.) or chronically 
administered to the animals in drinking water, and their liver or brain mitochondria were isolated and assayed [42-44]. Protocols were compatible with a blood circulating drug concentration, variable [45-47], though somewhat higher, than the $\sim 10^{-9} \mathrm{M}$ physiological one [48].

Alternatively, mitochondria were isolated first and then exposed to variable amounts of melatonin, down to $\sim 10^{-9} \mathrm{M}$ concentrations [49]. In these experiments, a significant specific enhancement of the eT activity of Complex I and Complex IV, was observed and more patently at a concentration of melatonin $\geq 10^{-6} \mathrm{M}$. The authors proposed that the increase of activity was related to: (i) optimization of the mitochondrial membrane fluidity, due to melatonin prevention of membrane lipid peroxidation [50]; (ii) direct scavenging of the $\mathrm{H}_{2} \mathrm{O}_{2}$ [51,52]; and (iii) stabilization of mitochondrial GSH [53-55].

Somewhat in contrast, Lopez, A., et al. [37] have shown that melatonin added to mice liver mitochondria at concentrations from $1 \mathrm{nM}$ to $1 \mathrm{mM}$ is able to decrease respiration in a concentration-dependent manner, by inhibiting the ADP-dependent state 4 to state 3 transition. In the same line, Reyes-Toso [56] observed that melatonin added in vitro to mitochondria or chronically administered to the animals in the diet inhibits the substrate-induced (ADP) state 4 to state 3 transition, suggesting that this might protect mitochondria from oxidative damage. Our investigation on HaCaT keratinocytes allowed us to study the effect of nanomolar melatonin, without losing the contribution of the nuclear signaling. Interestingly, only under these conditions, it has been possible to observe the enhancement of the nNOS expression and the depression of mitochondrial activity (Figure 6).

Figure 6. Melatonin and the "keratinocyte hypothesis". At nanomolar and sub-nanomolar melatonin concentration, a melatonin-receptor-mediated transient nNOS overexpression is triggered. At this stage, calmodulin can predominantly interact with nNOS, leading to production of $\mathrm{NO}$ and modulation of mitochondrial function. Upon increasing the external concentration of melatonin $(>1 \mathrm{nM})$ or its time of incubation, its intracellular concentration also rises: under these conditions, melatonin binds/inactivates calmodulin ( $\mathrm{CaCaM})$ leading to nNOS inhibition [57,58]. (a) Schematic drawing of melatonin traffic and signaling in a keratinocyte (HaCaT cells); (b) How the co-existing equilibrium of melatonin with calmodulin and NOS may affect NOS activity. Intracellular melatonin gradient (orange) and nNOS expression/activity (blue).

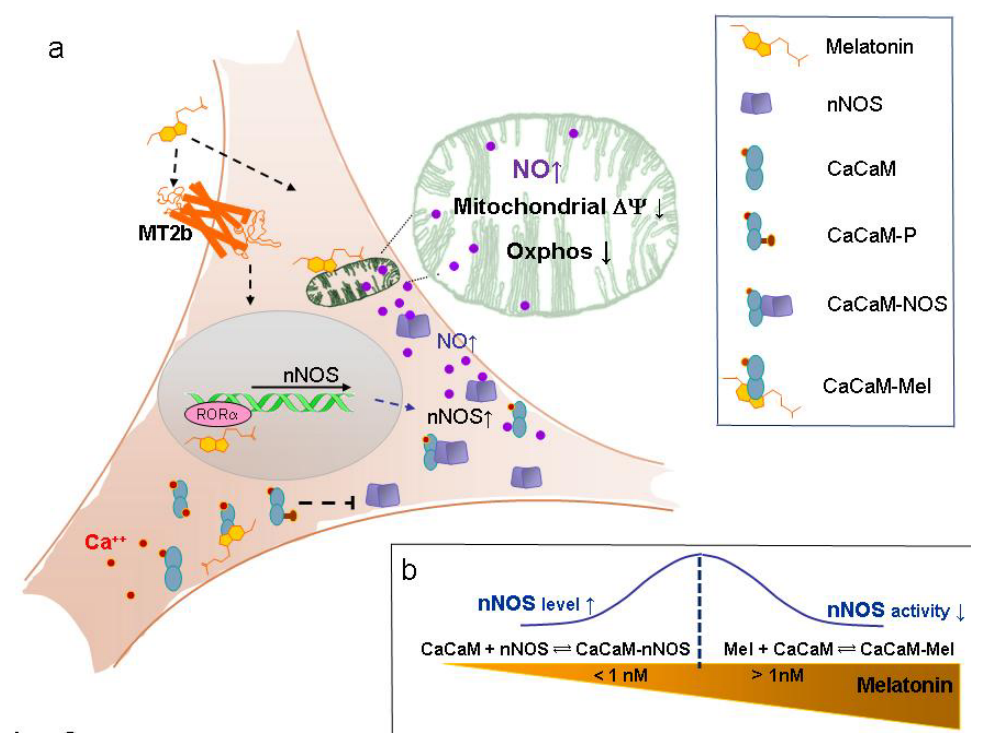




\subsubsection{Nanomolar Melatonin, nNOS Synthesis and Involvement of Complex IV}

Keratinocytes (HaCat cells), incubated for up to $15 \mathrm{~h}$ with nanomolar melatonin, after 6-8 h, display a transient rise of the nNOS and accumulate NOx (nitrite/nitrate) in the culture medium. The nNOS protein synthesis lags behind the rise of the corresponding nNOS mRNA: the protein increases transiently, and within hours, returns back to its basal level; the $\sim 2 \mathrm{~h}$ shift between the protein and the mRNA synthesis is consistent with a nuclear DNA-dependent pathway. Following incubation with nanomolar melatonin and on a time scale similar to that of both the nNOS changes and the NOx accumulation, the mitochondrial respiration becomes slightly, but significantly, depressed $(\sim 10 \%)$. The mitochondrial membrane potential, instead, decreases to a larger extent, by $\sim 20 \%$, suggesting that under these conditions and at least in keratinocytes mitochondria, the mechanism(s) responsible for maintenance of $\Delta \Psi$ are more affected than respiration [59]. This observation is compatible with the hypothesis that, as a cell responds to melatonin, a small amount of free NO, nanomolar or less [60], is made available in the mitochondrial environment. NO, in fact, is able to rapidly and reversibly inhibit Complex IV in turnover with electrons and oxygen [61], a reaction whose occurrence has been demonstrated at all integration levels of the enzyme, from purified to fully integrated, in intact mitochondria and in cells $[39,62,63]$. Synchronously with the down regulation of the respiratory chain, we have also observed a decrease of the cell ability to synthesize ATP increased production of glycolytic ATP, a behavior originally observed in astrocytes [64], the so-called Warburg effect [65].

Taken together, these findings suggest that nanomolar melatonin administered to intact HaCaT cells transiently activates the nNOS synthesis, with production of NO and reversible inhibition of Complex IV $[61,62,66]$. This leads, in turn, to a transient metabolic shift towards glycolysis [28]. It is worth recalling, in fact, that depending on the mechanism by which NO reacts with Complex IV, it is possible to detect either a physiological modulation of the electron transfer through the respiratory chain or a more persistent inhibition of mitochondrial respiration [63,67]. Relevant parameters controlling the reaction mechanism were shown to be the cell oxygenation state, the electron flux through the respiratory chain and, indeed, the NO concentration [63,68-70]. The fraction of mitochondria in state 3 and state 4 respiration is also important, as state 3 mitochondria are more prone to Complex IV nitrosylation (persistent inhibition) [71].

Based on independent measurements [68], under normal conditions of cell/tissues oxygenation and supply of mitochondrial reducing substrates, a pulse of NO, limited in extent and time, would lead to formation of a labile Complex $\mathrm{IV}_{-} \mathrm{NO}_{2}{ }^{-}$derivative. Interestingly, and relevant to the melatonin effects herein described, the activity of Complex IV is promptly recovered upon decreasing the NO bioavailability.

Melatonin, at pharmacological concentrations $\left(10^{-6} \mathrm{M}-10^{-3} \mathrm{M}\right)$, either by signaling (Figure 1) or acting as a radical scavenger, optimizes the eT within the respiratory chain [16] and referenced therein cited, likely minimizing the effects of the NO inhibition of Complex IV. It is tempting to speculate that when the inhibition of Complex IV by NO prevails over the optimization of the electron transfer, then the radical scavenging capacity of melatonin might become insufficient to compensate for inhibition [63]. We suggest that this occurs at $\sim 10^{-9} \mathrm{M}$ melatonin in the extracellular environment, a concentration far too low to be effective in radical scavenging, but apparently ideal to activate the receptor-mediated 
nNOS chemistry: the result is a transient release of NO with control of both the rate of respiration and the ATPoxpнos synthesis. As expected, the Warburg effect is also clearly observed and, as a side effect, a higher fraction of $\mathrm{O}_{2}$ becomes available for close by cells, the so called $\mathrm{O}_{2}$-diversion [72]. Within the limits of a comparison between a cell culture system and an in vivo state, we suggest that the events involving $10^{-9} \mathrm{M}$ melatonin and mitochondria are physiological and might occur in a circadian context.

Thus, under the conditions herein used to treat keratinocytes, $1 \mathrm{nM}$ melatonin in the external medium depressed cell respiration and transiently increased the nNOS expression. Both effects were reverted upon increasing the concentration of melatonin or maintaining the cells in the presence of $1 \mathrm{nM}$ melatonin for longer incubation times. The mechanism through which low melatonin concentrations in the extracellular medium might trigger the nNOS expression and, apparently, in a paradoxical biphasic mode, remains unclear. It is tempting to speculate that a time and concentration-dependent feed-back controls the effects of melatonin on the nNOS and that the basis of this control might involve the melatonin-calmodulin interaction and signaling [57].

In this frame, when the extracellular hormone concentration is low (nanomolar or less), the nuclear mediated nNOS activation occurs, also sustained by the cell availability of calmodulin (high affinity nNOS cofactor [73]). As the incubation time increases, the intracellular concentration of melatonin (and/or its metabolites) increases, too (Figure 6b). At this stage, due to the high affinity of melatonin for calmodulin [74] a competition between melatonin and nNOS for calmodulin occurs, inducing progressive nNOS inhibition [58] (Figure 6).

The existence of such equilibrium, if confirmed, would explain the biphasic behavior observed, also reconciling some discrepancies in the literature about the effects of melatonin, both on mitochondria and NOS.

\section{Experimental Section}

\subsection{Chemicals}

Dulbecco's modified Eagle's medium (DMEM) and fetal bovine serum (FBS) were from Invitrogen Life Technologies (GIBCO, Paisley, UK) and from PAA (Linz, Austria). Melatonin, JC-1 and all other reagents were from Sigma (St. Louis, MO, USA), unless otherwise specified. Real-time PCR reagents were from Stratagene (Santa Clara, CA, USA).

\subsection{Cell Culture}

HaCaT cells were grown in Dulbecco's modified Eagle's medium (DMEM), 10\% fetal bovine serum (FBS), containing $4.5 \mathrm{~g} / \mathrm{L}$ glucose, $0.05 \mathrm{mg} / \mathrm{mL}$ gentamycin and $2 \mathrm{mM}$ L-glutamine, in $25 \mathrm{~cm}^{2}$ flasks or multi-well plates. Cultures were maintained at $37{ }^{\circ} \mathrm{C}$, under $5 \% \mathrm{CO}_{2}$ and $95 \%$ air. Before melatonin treatment, cells were grown for $\sim 24 \mathrm{~h}$ in $1 \mathrm{~g} / \mathrm{L}$ glucose DMEM, w/o FBS and phenol red. When required, cell lysis was carried out by TRIzol or CelLytic ${ }^{\mathrm{TM}} \mathrm{M}$ Cell Lysis reagent in the presence of Protease Inhibitor Cocktail (1:100); protein content was determined by the Bradford reaction, and citrate synthase activity was assayed as representative of the mitochondrial mass. 


\section{3. $n N O S$ mRNA Determination}

The nNOS mRNA was determined according to the protocol detailed in [28]; briefly, HaCaT cells $\left(\sim 3 \times 10^{6}\right.$ cells $)$ were harvested and total RNA isolated; the reverse transcription was carried out using SideStep $^{\text {TM }}$ II QPCR cDNA Synthesis Kit (Agilent Technologies, Santa Clara, CA, USA). The QRT-PCR was performed using a Stratagene Mx3005p System (Agilent Technologies, Santa Clara, CA, USA). All reactions have been carried out in triplicate.

\section{4. nNOS Detection by Western Blot}

HaCaT cells were lysed with CelLytic ${ }^{\mathrm{TM}} \mathrm{M}$ reagent (Sigma) in the presence of protease inhibitors (Sigma). The proteins were separated on 10\% SDS-PAGE gels and transferred on nitrocellulose membranes (Whatman, GE Halthcare UK, Buckinghamshire, UK) $1 \mathrm{~h}$ at $100 \mathrm{~mA}$. After $2 \mathrm{~h}$ blocking (PBS with $0.1 \%$ tween and 3\% BSA), the membrane was incubated overnight at $4{ }^{\circ} \mathrm{C}$ with primary rabbit polyclonal anti-nNOS antibodies (from BD Transduction Laboratories, Buccinasco, MI, Italy); $\alpha$ tubulin was used as the reference. A secondary ECL TM anti-rabbit antibody HRP (Jackson, Baltimore, PA, USA) was thereafter incubated $1 \mathrm{~h}$ at $25{ }^{\circ} \mathrm{C}$ and chemiluminescence determined (Amersham, GE Halthcare UK, Buckinghamshire, UK). Densitometric analysis was carried out by the KODAK 1D Image Analysis Software (Eastman Kodak Company, Rochester, NY, USA).

\subsection{Nitrite/Nitrate (NOx) Determination}

Accumulation of the NOx in the culture medium of HaCaT cells $\left(\sim 2.5 \times 10^{5}\right.$ cells $\left./ \mathrm{mL}\right)$ was measured after $6 \mathrm{~h}$ and $8 \mathrm{~h}$ exposure to melatonin at the given concentrations or at different times of incubation with $1 \mathrm{nM}$ melatonin (see text). The NOx content was determined fluorometrically (Fluorometric Assay Kit, Cayman Chemical Co., Ann Arbor, MI, USA).

\subsection{Cell Respiration}

HaCaT cells, grown overnight in an antibiotic/FBS-free DMEM medium, were incubated $8 \mathrm{~h}$ with increasing melatonin concentrations $(1,10,100 \mathrm{nM})$; when required, the nNOS inhibitor, $7 \mathrm{~N}$, was added $(500 \mathrm{nM}) 30 \mathrm{~min}$ before the measurement. For the assay, cells were resuspended in Hank's buffer containing $5.5 \mathrm{mM}$ glucose at a final cell density, $3.3 \times 10^{6}$ cells $/ \mathrm{mL}$. Cell respiration was evaluated using high resolution respirometry (2k-Oxygraph OROBOROS Instruments, Innsbruck, Austria).

\subsection{Mitochondrial Membrane Potential}

The mitochondrial $\mathrm{H}^{+}$electrochemical potential gradient of intact cells $\left(\Delta \mu \mathrm{H}^{+}\right)$was evaluated following the mitochondrial electrophoretic accumulation of JC-1 (Sigma) [75]. In the presence of the ionophore nigericin, converting $\Delta \mathrm{pH}$ into $\Delta \Psi$ [76], the fluorescence reaches a maximum, whose level depends upon the membrane potential value. The fluorescence signal is rapidly dissipated by $0.2 \mu \mathrm{M}$ valinomycin $(\Delta \Psi \approx 0)$, thus allowing a $\Delta F$ to be evaluated (proportional to the membrane potential). 


\subsection{ATP Measurements}

The ATP concentration was quantified by chemiluminescence, as described in [28]. Briefly, cells were incubated with $1 \mathrm{nM}$ melatonin for $6 \mathrm{~h}$. The rate of ATP production was evaluated after cell membrane permeabilization with $60 \mu \mathrm{g} / \mathrm{mL}$ digitonin, $20 \mathrm{~min}$ at $25^{\circ} \mathrm{C} ; 20 \mathrm{mM}$ succinate and $0.5 \mathrm{mM}$ ADP were thereafter added, in the presence of $4 \mu \mathrm{M}$ rotenone, to induce ATP synthesis. Measurements were performed using the ATPlite kit (Perkin Elmer, Waltham, MA, USA), on a VICTOR ${ }^{\text {TM }}$ Multilabel Counter (Perkin Elmer, Waltham, MA, USA) equipped with 96-well (white) plates.

\subsection{Lactate Measurements}

Cells $\left(\sim 3 \times 10^{6}\right.$ cells $)$, have been incubated $6 \mathrm{~h}$ with melatonin, $1 \mathrm{nM}$, and then, the lactate was measured. In order to energetically synchronize the cells, after the first $2 \mathrm{~h}$, incubation cells were starved $1 \mathrm{~h}$ from glucose. Thereafter, glucose, $1 \mathrm{mM}$, was re-added to the cells for a further $3 \mathrm{~h}$. Lactate determinations have been carried out in the absence of myxothiazol and antimycin A or in their presence $(10 \mu \mathrm{M}$ each) to fully inhibit OXPHOS. The lactate concentration was determined spectrophotometrically on the cell supernatant collected by centrifugation $\left(1000 \times g\right.$, at $\left.4{ }^{\circ} \mathrm{C}, 10 \mathrm{~min}\right)$.

\subsection{Statistics}

The number of independent measurements is indicated in the figure legend. Significance was determined using the Student $t$-test, run by Excel (Microsoft Windows platform). The error bars correspond to the standard error of the mean (SEM); all $p$-values correspond to two-sided sample $t$-test, assuming unequal variances. A $p$-value $\leq 0.05$ was considered significant.

\section{Conclusions}

Based on our results, the physiological meaning of the effects induced by melatonin on the nNOS, and, thereby, on cell bioenergetics, is purely hypothetical, demanding further assessment and independent evaluation. All together, the experimental evidence points to two mechanistically-independent activities exerted by melatonin at the mitochondrial level. The first one is based on the antioxidant radical scavenging properties of melatonin: this is best observed at a high concentration of melatonin $\left(\geq 10^{-6} \mathrm{M}\right)$; the second one is more consistent with a hormonal-like function and appears to be nuclear-dependent, possibly receptor-mediated, thus requiring a suitable time of cell incubation with nanomolar amounts of melatonin. Interestingly enough, these extracellular concentration values are compatible with those reached in our body during night peak, $\sim 100-200 \mathrm{pg} / \mathrm{mL}$ [48,77], i.e., $\sim 1 \mathrm{nM}$ melatonin. We believe that under these conditions, the intra-cellular concentration of melatonin increases gradually and allows its accumulation in the different cell compartments. In this respect, it is worth mentioning that the evaluation of the melatonin activity at the mitochondrial level can be particularly difficult in vivo, if we consider that: melatonin can be imported and accumulated in the mitochondrion [37], while metabolites of melatonin retain a substantial bioactivity [45]. Furthermore, calmodulin, in the cell, is in equilibrium with both melatonin and nNOS, indeed, among other targets: this peculiar state should be considered when addressing the melatonin effects on mitochondria. With these premises, the comparison between data obtained using different experimental approaches may 
not be straightforward. In conclusion, also based on the literature, our data suggest that melatonin controls mitochondrial efficiency at different levels, by: (i) favoring the eT through the respiratory chain, in a concentration-dependent manner and independently on nuclear-DNA-mediated reactions; while (ii) causing a mild transient inhibition of Complex IV, with a mitochondrial glycolytic shift, an effect mediated by nuclear signaling in a circadian compatible time-window.

\section{Acknowledgements}

The authors wish to thank Caterina Grillo for helping in performing some of the QRT-PCR experiments and Thomas J.J. Blanck for fruitful discussion. Work partially supported by Ministero dell'Istruzione, dell'Università e della Ricerca of Italy (PRIN 20107Z8XBW_005 and FIRB RBIN06E9Z8 to P.S.) and by the PNR-CNR Aging Program 2012-2014.

\section{Conflict of Interest}

The authors declare no conflict of interest.

\section{References}

1. Maharaj, D.S.; Glass, B.D.; Daya, S. Melatonin: New places in therapy. Biosci. Rep. 2007, 27, 299-320.

2. Reiter, R.J.; Paredes, S.D.; Manchester, L.C.; Tan, D.X. Reducing oxidative/nitrosative stress: A newly-discovered genre for melatonin. Crit. Rev. Biochem. Mol. Biol. 2009, 44, 175-200.

3. Conti, A.; Conconi, S.; Hertens, E.; Skwarlo-Sonta, K.; Markowska, M.; Maestroni, J.M. Evidence for melatonin synthesis in mouse and human bone marrow cells. J. Pineal Res. 2000, 28, 193-202.

4. Slominski, A.; Tobin, D.J.; Zmijewski, M.A.; Wortsman, J.; Paus, R. Melatonin in the skin: Synthesis, metabolism and functions. Trends Endocrinol. Metab. 2008, 19, 17-24.

5. Champier, J.; Claustrat, B.; Besancon, R.; Eymin, C.; Killer, C.; Jouvet, A.; Chamba, G.; Fevre-Montange, M. Evidence for tryptophan hydroxylase and hydroxy-indol- $O$-methyl-transferase mRNAs in human blood platelets. Life Sci. 1997, 60, 2191-2197.

6. Carrillo-Vico, A.; Calvo, J.R.; Abreu, P.; Lardone, P.J.; Garcia-Maurino, S.; Reiter, R.J.; Guerrero, J.M. Evidence of melatonin synthesis by human lymphocytes and its physiological significance: Possible role as intracrine, autocrine, and/or paracrine substance. FASEB J. 2004, 18, 537-539.

7. Liu, C.; Fukuhara, C.; Wessel, J.H., 3rd; Iuvone, P.M.; Tosini, G. Localization of Aa-nat mRNA in the rat retina by fluorescence in situ hybridization and laser capture microdissection. Cell Tissue Res. 2004, 315, 197-201.

8. Reiter, R.J.; Tan, D.X. What constitutes a physiological concentration of melatonin? J. Pineal Res. 2003, 34, 79-80.

9. Escames, G.; Acuna-Castroviejo, D. Melatonin, synthetic analogs, and the sleep/wake rhythm. Rev. Neurol. 2009, 48, 245-254. 
10. Morris, C.J.; Aeschbach, D.; Scheer, F.A. Circadian system, sleep and endocrinology. Mol. Cell. Endocrinol. 2012, 349, 91-104.

11. Dollins, A.B.; Zhdanova, I.V.; Wurtman, R.J.; Lynch, H.J.; Deng, M.H. Effect of inducing nocturnal serum melatonin concentrations in daytime on sleep, mood, body temperature, and performance. Proc. Natl. Acad. Sci. USA 1994, 91, 1824-1828.

12. Luchetti, F.; Canonico, B.; Betti, M.; Arcangeletti, M.; Pilolli, F.; Piroddi, M.; Canesi, L.; Papa, S.; Galli, F. Melatonin signaling and cell protection function. FASEB J. 2010, 24, 3603-3624.

13. Ciftci, M.; Bilici, D.; Kufrevioglu, O.I. Effects of melatonin on enzyme activities of glucose-6-phosphate dehydrogenase from human erythrocytes in vitro and from rat erythrocytes in vivo. Pharmacol. Res. 2001, 44, 7-11.

14. Martin, V.; Herrera, F.; Carrera-Gonzalez, P.; Garcia-Santos, G.; Antolin, I.; Rodriguez-Blanco, J.; Rodriguez, C. Intracellular signaling pathways involved in the cell growth inhibition of glioma cells by melatonin. Cancer Res. 2006, 66, 1081-1088.

15. Korkmaz, A.; Ma, S.; Topal, T.; Rosales-Corral, S.; Tan, D.X.; Reiter, R.J. Glucose: A vital toxin and potential utility of melatonin in protecting against the diabetic state. Mol. Cell. Endocrinol. 2012, 349, 128-137.

16. Acuna-Castroviejo, D.; Escames, G.; Rodriguez, M.I.; Lopez, L.C. Melatonin role in the mitochondrial function. Front. Biosci. 2007, 12, 947-963.

17. Reiter, R.J.; Tan, D.X.; Rosales-Corral, S.; Manchester, L.C. The universal nature, unequal distribution and antioxidant functions of melatonin and its derivatives. Mini Rev. Med. Chem. 2013, 13, 373-384.

18. Poeggeler, B.; Reiter, R.J.; Tan, D.X.; Chen, L.D.; Manchester, L.C. Melatonin, hydroxyl radical-mediated oxidative damage, and aging: A hypothesis. J. Pineal Res. 1993, 14, 151-168.

19. Poeggeler, B.; Thuermann, S.; Dose, A.; Schoenke, M.; Burkhardt, S.; Hardeland, R. Melatonin's unique radical scavenging properties-Roles of its functional substituents as revealed by a comparison with its structural analogs. J. Pineal Res. 2002, 33, 20-30.

20. Poeggeler, B.; Saarela, S.; Reiter, R.J.; Tan, D.X.; Chen, L.D.; Manchester, L.C.; Barlow-Walden, L.R. Melatonin-A highly potent endogenous radical scavenger and electron donor: New aspects of the oxidation chemistry of this indole accessed in vitro. Ann. N. Y. Acad. Sci. 1994, 738, 419-420.

21. Mahal, H.S.; Sharma, H.S.; Mukherjee, T. Antioxidant properties of melatonin: A pulse radiolysis study. Free Radic. Biol. Med. 1999, 26, 557-565.

22. Srinivasan, V.; Spence, D.W.; Pandi-Perumal, S.R.; Brown, G.M.; Cardinali, D.P. Melatonin in mitochondrial dysfunction and related disorders. Int. J. Alzheimers Dis. 2011, doi:10.4061/2011/326320.

23. Griefahn, B.; Brode, P.; Remer, T.; Blaszkewicz, M. Excretion of 6-hydroxymelatonin sulfate (6-OHMS) in siblings during childhood and adolescence. Neuroendocrinology 2003, 78, 241-243.

24. Bergiannaki, J.D.; Soldatos, C.R.; Paparrigopoulos, T.J.; Syrengelas, M.; Stefanis, C.N. Low and high melatonin excretors among healthy individuals. J. Pineal Res. 1995, 18, 159-164.

25. Grof, E.; Grof, P.; Brown, G.M.; Arato, M.; Lane, J. Investigations of melatonin secretion in man. Prog. Neuropsychopharmacol. Biol. Psychiatry 1985, 9, 609-612.

26. Wetterberg, L.; Iselius, L.; Lindsten, J. Genetic regulation of melatonin excretion in urine. A preliminary report. Clin. Genet. 1983, 24, 399-402. 
27. Galecki, P.; Szemraj, J.; Bartosz, G.; Bienkiewicz, M.; Galecka, E.; Florkowski, A.; Lewinski, A.; Karbownik-Lewinska, M. Single-nucleotide polymorphisms and mRNA expression for melatonin synthesis rate-limiting enzyme in recurrent depressive disorder. J. Pineal Res. 2010, 48, 311-317.

28. Arese, M.; Magnifico, M.C.; Mastronicola, D.; Altieri, F.; Grillo, C.; Blanck, T.J.; Sarti, P. Nanomolar melatonin enhances nNOS expression and controls HaCaT-cells bioenergetics. IUBMB Life 2012, 64, 251-258.

29. Cleeter, M.W.; Cooper, J.M.; Darley-Usmar, V.M.; Moncada, S.; Schapira, A.H. Reversible inhibition of cytochrome c oxidase, the terminal enzyme of the mitochondrial respiratory chain, by nitric oxide. Implications for neurodegenerative diseases. FEBS Lett. 1994, 345, 50-54.

30. Brown, G.C.; Bolanos, J.P.; Heales, S.J.; Clark, J.B. Nitric oxide produced by activated astrocytes rapidly and reversibly inhibits cellular respiration. Neurosci. Lett. 1995, 193, 201-204.

31. Kalinchuk, A.V.; Stenberg, D.; Rosenberg, P.A.; Porkka-Heiskanen, T. Inducible and neuronal nitric oxide synthases (NOS) have complementary roles in recovery sleep induction. Eur. J. Neurosci. 2006, 24, 1443-1456.

32. Tsikas, D.; Gutzki, F.M.; Stichtenoth, D.O. Circulating and excretory nitrite and nitrate as indicators of nitric oxide synthesis in humans: Methods of analysis. Eur. J. Clin. Pharmacol. 2006, 62, 51-59.

33. Chen, L.; Majde, J.A.; Krueger, J.M. Spontaneous sleep in mice with targeted disruptions of neuronal or inducible nitric oxide synthase genes. Brain Res. 2003, 973, 214-222.

34. Leonard, T.O.; Lydic, R. Pontine nitric oxide modulates acetylcholine release, rapid eye movement sleep generation, and respiratory rate. J. Neurosci. 1997, 17, 774-785.

35. Alonso, M.; Collado, P.S.; Gonzalez-Gallego, J. Melatonin inhibits the expression of the inducible isoform of nitric oxide synthase and nuclear factor kappa B activation in rat skeletal muscle. J. Pineal Res. 2006, 41, 8-14.

36. Petrosillo, G.; Moro, N.; Ruggiero, F.M.; Paradies, G. Melatonin inhibits cardiolipin peroxidation in mitochondria and prevents the mitochondrial permeability transition and cytochrome c release. Free Radic. Biol. Med. 2009, 47, 969-974.

37. Lopez, A.; Garcia, J.A.; Escames, G.; Venegas, C.; Ortiz, F.; Lopez, L.C.; Acuna-Castroviejo, D. Melatonin protects the mitochondria from oxidative damage reducing oxygen consumption, membrane potential, and superoxide anion production. J. Pineal Res. 2009, 46, 188-198.

38. Hevia, D.; Sainz, R.M.; Blanco, D.; Quiros, I.; Tan, D.X.; Rodriguez, C.; Mayo, J.C. Melatonin uptake in prostate cancer cells: Intracellular transport versus simple passive diffusion. J. Pineal Res. 2008, 45, 247-257.

39. Moncada, S.; Erusalimsky, J.D. Does nitric oxide modulate mitochondrial energy generation and apoptosis? Nat. Rev. Mol. Cell Biol. 2002, 3, 214-220.

40. Sarti, P.; Forte, E.; Giuffre, A.; Mastronicola, D.; Magnifico, M.C.; Arese, M. The chemical interplay between nitric oxide and mitochondrial cytochrome c oxidase: Reactions, effectors and pathophysiology. Int. J. Cell Biol. 2012, doi:10.1155/2012/571067.

41. Sgarbi, G.; Baracca, A.; Lenaz, G.; Valentino, L.M.; Carelli, V.; Solaini, G. Inefficient coupling between proton transport and ATP synthesis may be the pathogenic mechanism for NARP and Leigh syndrome resulting from the T8993G mutation in mtDNA. Biochem. J. 2006, 395, 493-500. 
42. Martin, M.; Macias, M.; Escames, G.; Reiter, R.J.; Agapito, M.T.; Ortiz, G.G.; Acuna-Castroviejo, D. Melatonin-induced increased activity of the respiratory chain complexes I and IV can prevent mitochondrial damage induced by ruthenium red in vivo. J. Pineal Res. 2000, $28,242-248$.

43. Okatani, Y.; Wakatsuki, A.; Reiter, R.J. Melatonin protects hepatic mitochondrial respiratory chain activity in senescence-accelerated mice. J. Pineal Res. 2002, 32, 143-148.

44. Jimenez-Ortega, V.; Cano, P.; Cardinali, D.P.; Esquifino, A.I. 24-Hour variation in gene expression of redox pathway enzymes in rat hypothalamus: Effect of melatonin treatment. Redox Rep. 2009, 14, 132-138.

45. Tan, D.X.; Manchester, L.C.; Terron, M.P.; Flores, L.J.; Reiter, R.J. One molecule, many derivatives: A never-ending interaction of melatonin with reactive oxygen and nitrogen species? J. Pineal Res. 2007, 42, 28-42.

46. Martin, M.; Macias, M.; Escames, G.; Leon, J.; Acuna-Castroviejo, D. Melatonin but not vitamins $\mathrm{C}$ and $\mathrm{E}$ maintains glutathione homeostasis in $t$-butyl hydroperoxide-induced mitochondrial oxidative stress. FASEB J. 2000, 14, 1677-1679.

47. Inarrea, P.; Casanova, A.; Alava, M.A.; Iturralde, M.; Cadenas, E. Melatonin and steroid hormones activate intermembrane $\mathrm{Cu}, \mathrm{Zn}$-superoxide dismutase by means of mitochondrial cytochrome P450. Free Radic. Biol. Med. 2011, 50, 1575-1581.

48. Zawilska, J.B.; Skene, D.J.; Arendt, J. Physiology and pharmacology of melatonin in relation to biological rhythms. Pharmacol. Rep. 2009, 61, 383-410.

49. Martin, M.; Macias, M.; Leon, J.; Escames, G.; Khaldy, H.; Acuna-Castroviejo, D. Melatonin increases the activity of the oxidative phosphorylation enzymes and the production of ATP in rat brain and liver mitochondria. Int. J. Biochem. Cell Biol. 2002, 34, 348-357.

50. Garcia, J.J.; Reiter, R.J.; Guerrero, J.M.; Escames, G.; Yu, B.P.; Oh, C.S.; Munoz-Hoyos, A. Melatonin prevents changes in microsomal membrane fluidity during induced lipid peroxidation. FEBS Lett. 1997, 408, 297-300.

51. Reiter, R.J.; Tan, D.X.; Manchester, L.C.; Qi, W. Biochemical reactivity of melatonin with reactive oxygen and nitrogen species: A review of the evidence. Cell Biochem. Biophys. 2001, 34, $237-256$.

52. Tan, D.X.; Manchester, L.C.; Reiter, R.J.; Qi, W.B.; Karbownik, M.; Calvo, J.R. Significance of melatonin in antioxidative defense system: Reactions and products. Biol. Signals Recept. 2000, 9, 137-159.

53. Acuna-Castroviejo, D.; Martin, M.; Macias, M.; Escames, G.; Leon, J.; Khaldy, H.; Reiter, R.J. Melatonin, mitochondria, and cellular bioenergetics. J. Pineal Res. 2001, 30, 65-74.

54. Leon, J.; Acuna-Castroviejo, D.; Sainz, R.M.; Mayo, J.C.; Tan, D.X.; Reiter, R.J. Melatonin and mitochondrial function. Life Sci. 2004, 75, 765-790.

55. Leon, J.; Acuna-Castroviejo, D.; Escames, G.; Tan, D.X.; Reiter, R.J. Melatonin mitigates mitochondrial malfunction. J. Pineal Res. 2005, 38, 1-9.

56. Reyes-Toso, C.F.; Rebagliati, I.R.; Ricci, C.R.; Linares, L.M.; Albornoz, L.E.; Cardinali, D.P.; Zaninovich, A. Effect of melatonin treatment on oxygen consumption by rat liver mitochondria. Amino Acids 2006, 31, 299-302. 
57. Soto-Vega, E.; Meza, I.; Ramirez-Rodriguez, G.; Benitez-King, G. Melatonin stimulates calmodulin phosphorylation by protein kinase C. J. Pineal Res. 2004, 37, 98-106.

58. Leon, J.; Escames, G.; Rodriguez, M.I.; Lopez, L.C.; Tapias, V.; Entrena, A.; Camacho, E.; Carrion, M.D.; Gallo, M.A.; Espinosa, A.; et al. Inhibition of neuronal nitric oxide synthase activity by $N^{1}$-acetyl-5-methoxykynuramine, a brain metabolite of melatonin. J. Neurochem. 2006, 98, 2023-2033.

59. Palacios-Callender, M.; Quintero, M.; Hollis, V.S.; Springett, R.J.; Moncada, S. Endogenous NO regulates superoxide production at low oxygen concentrations by modifying the redox state of cytochrome c oxidase. Proc. Natl. Acad. Sci. USA 2004, 101, 7630-7635.

60. Mastronicola, D.; Genova, M.L.; Arese, M.; Barone, M.C.; Giuffre, A.; Bianchi, C.; Brunori, M.; Lenaz, G.; Sarti, P. Control of respiration by nitric oxide in Keilin-Hartree particles, mitochondria and SH-SY5Y neuroblastoma cells. Cell. Mol. Life Sci. 2003, 60, 1752-1759.

61. Sarti, P.; Giuffrè, A.; Barone, M.C.; Forte, E.; Mastronicola, D.; Brunori, M. Nitric oxide and cytochrome oxidase: Reaction mechanisms from the enzyme to the cell. Free Radic. Biol. Med. 2003, 34, 509-520.

62. Cooper, C.E.; Mason, M.G.; Nicholls, P. A dynamic model of nitric oxide inhibition of mitochondrial cytochrome c oxidase. Biochim. Biophys. Acta 2008, 1777, 867-876.

63. Sarti, P.; Forte, E.; Mastronicola, D.; Giuffre, A.; Arese, M. Cytochrome c oxidase and nitric oxide in action: Molecular mechanisms and pathophysiological implications. Biochim. Biophys. Acta 2012, 1817, 610-619.

64. Almeida, A.; Almeida, J.; Bolanos, J.P.; Moncada, S. Different responses of astrocytes and neurons to nitric oxide: The role of glycolytically generated ATP in astrocyte protection. Proc. Natl. Acad. Sci. USA 2001, 98, 15294-15299.

65. Warburg, O. On respiratory impairment in cancer cells. Science 1956, 124, 269-270.

66. Brown, G.C.; Cooper, C.E. Nanomolar concentrations of nitric oxide reversibly inhibit synaptosomal respiration by competing with oxygen at cytochrome oxidase. FEBS Lett. 1994, 356, 295-298.

67. Cooper, C.E.; Brown, G.C. The inhibition of mitochondrial cytochrome oxidase by the gases carbon monoxide, nitric oxide, hydrogen cyanide and hydrogen sulfide: Chemical mechanism and physiological significance. J. Bioenerg. Biomembr. 2008, 40, 533-539.

68. Sarti, P.; Giuffrè, A.; Forte, E.; Mastronicola, D.; Barone, M.C.; Brunori, M. Nitric oxide and cytochrome $c$ oxidase: Mechanisms of inhibition and NO degradation. Biochem. Biophys. Res. Commun. 2000, 274, 183-187.

69. Brunori, M.; Forte, E.; Arese, M.; Mastronicola, D.; Giuffre, A.; Sarti, P. Nitric oxide and the respiratory enzyme. Biochim. Biophys. Acta 2006, 1757, 1144-1154.

70. Mason, M.G.; Nicholls, P.; Wilson, M.T.; Cooper, C.E. Nitric oxide inhibition of respiration involves both competitive (heme) and noncompetitive (copper) binding to cytochrome c oxidase. Proc. Natl. Acad. Sci. USA 2006, 103, 708-713.

71. Brookes, P.S.; Kraus, D.W.; Shiva, S.; Doeller, J.E.; Barone, M.C.; Patel, R.P.; Lancaster, J.R., Jr.; Darley-Usmar, V. Control of mitochondrial respiration by $\mathrm{NO}^{*}$, effects of low oxygen and respiratory state. J. Biol. Chem. 2003, 278, 31603-31609. 
72. Trimmer, B.A.; Aprille, J.R.; Dudzinski, D.M.; Lagace, C.J.; Lewis, S.M.; Michel, T.; Qazi, S.; Zayas, R.M. Nitric oxide and the control of firefly flashing. Science 2001, 292, 2486-2488.

73. Zoche, M.; Bienert, M.; Beyermann, M.; Koch, K.W. Distinct molecular recognition of calmodulin-binding sites in the neuronal and macrophage nitric oxide synthases: A surface plasmon resonance study. Biochemistry 1996, 35, 8742-8747.

74. Romero, M.P.; Garcia-Perganeda, A.; Guerrero, J.M.; Osuna, C. Membrane-bound calmodulin in Xenopus laevis oocytes as a novel binding site for melatonin. FASEB J. 1998, 12, 1401-1408.

75. Reers, M.; Smith, T.W.; Chen, L.B. J-aggregate formation of a carbocyanine as a quantitative fluorescent indicator of membrane potential. Biochemistry 1991, 30, 4480-4486.

76. Reed, P.W. Ionophores. Methods Enzymol. 1979, 55, 435-454.

77. Pandi-Perumal, S.R.; Srinivasan, V.; Maestroni, G.J.; Cardinali, D.P.; Poeggeler, B.; Hardeland, R. Melatonin: Nature's most versatile biological signal? FEBS J. 2006, 273, 2813-2838.

(C) 2013 by the authors; licensee MDPI, Basel, Switzerland. This article is an open access article distributed under the terms and conditions of the Creative Commons Attribution license (http://creativecommons.org/licenses/by/3.0/). 